\title{
Studies on Manifold Abnormalities at Meiosis in Petunia $(2 n=14)$
}

\author{
V. Padmaja \\ Department of Botany, Andhra University, Waltair 530 003, India
}

Accepted December 17, 1986

Deviations from normal meiotic process are significant from evolutionary point of veiw, as the behaviour of chromosomes at meiosis controls the distribution of genes and thus boost up the genetic variability in the otherwise conservative meiotic system. The precise and specific events of meiosis are controlled by a large number of genes, denoted as the meiotic genes with distinct cytogenetic effects. Since the discovery by Gowen and Gowen (1922) of the first meiotic mutant C(3)G in Drosophila, the genotypic control of meiotic process has been examined in several reviews (John and Lewis 1965, Riley 1966, Taylor 1967, Gottschalk 1968, Baker et al. 1976 and Kaul and Murthy 1985).

In an experiment designed to study the transmission of extra chromosome in the primary trisomics of Petunia axillaris (Lam.) B.S.P., $(2 \mathrm{n}=14)$, two mutants T4-1 and T1-50 characterised by atypical meiotic behaviour were identified in Trisomic $\times$ diploid crosses. One of these plants showing stickiness of chromosomes was a diploid, while the other was aneuploid, associated with chromosomal mosaicism and manifold meiotic abnormalities.

\section{Materials and methods}

Primary trisomics, the parents of the abnormal plants were obtained from synthetic triploid $\times$ diploid crosses of white flowered variety of $P$. axillaris (Lam.) B.S.P. The two meiotic mutants T4-1 and T1-50 were obtained from Triplo- $4 \times$ diploid and Triplo- $1 \times$ diploid crosses respectively. Flower buds were fixed between 9 and 10 AM in 1:4 acetic alcohol and smear preparations were made in $1 \%$ acetocarmine. Diameter of pollen mother cells and pollen grains were measured with the help of ocular micrometer.

\section{Results and discussion}

a) Meiotic chromosome stickiness

In plant number $T_{4-1}$ meiotic divisions were asynchronous, unlike in controls. The premeiotic mitotic divisions, the divisions in the surrounding tapetal cells as well as the prepachytene stages of meiosis were apparently normal. At post pachytene stages in general and at diplotene in particular, the chromosome matrix was impaired, resulting in an ill defined chromosome outline. The chromosomes showed a tendency to congregate together into groups, as a result of generalised clumping. Subsequently, the chromosomes have apparently lost their identity and were represented in the form of compact, sticky masses of variable sizes, shapes and number (Figs. 1b, c, d). Visual classification into smaller and larger chromatin masses and the frequencies of PMCs with variable combinations of smaller and larger clumps is presented in Table 1 . In $15.98 \%$ of the cells, chromatin was in the form of shattered particles (Fig. 1a).

Abnormalities such as non-alignment of chromatin masses at the equator, non-disjunction, and presence of one to several laggards were frequently encountered at first and second an- 
aphase stages (Figs. 1e,f). Analysis of sporads revealed a range of 1 to 9 microspores (Fig. 2i). Data on pollen sterility, seed set and the segregational patterns of the mutant in $F_{1}$ and $\mathrm{F}_{2}$ generations is presented in Table 2.

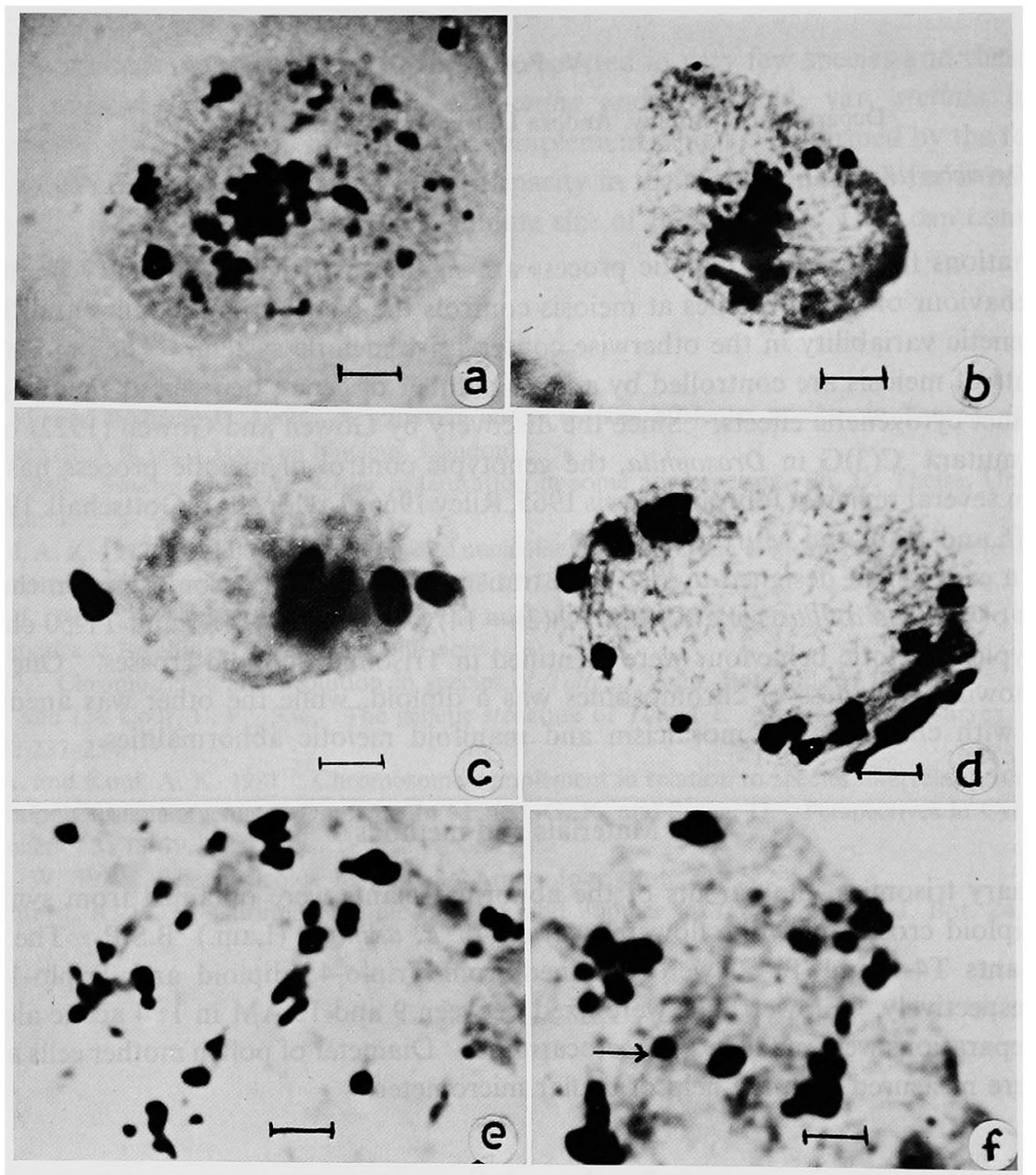

Fig. 1. Pollen mother cells from $\mathbf{T}_{4-1}$ displaying different phases of stickiness. a, chromosomes in the form of shattered mases. b, sticky metaphase. c, metaphase I showing two large and three small clumps. d, sticky anaphase I. e, second division showing several sticky masses. f, telophase II showing laggards forming micronuclei (arrow). Bar represents $10 \mu \mathrm{m}$.

Table 1. Frequency of PMC with large and small sticky chromatin clumps at meta- anaphase in $\mathbf{T}_{4-1}$

\begin{tabular}{llcr}
\hline \hline \multirow{2}{*}{ S. no. } & \multicolumn{1}{c}{ Sticky pattern } & \multicolumn{2}{c}{ Frequency of PMC } \\
\cline { 3 - 4 } & & No. & $\%$ \\
\hline 1 & Single chromatin clump & 12 & 4.91 \\
2 & Two large chromatin clumps & 17 & 6.96 \\
3 & 2-5 large clumps+1-5 small clumps & 35 & 14.34 \\
4 & 2-5 large clumps+more than 5 small clumps & 86 & 35.24 \\
5 & 6-10 large clumps+1-5 small clumps & 19 & 7.78 \\
6 & 6-10 large clumps+more than 5 small clumps & 36 & 14.75 \\
7 & Shattered chromatin & 39 & 15.98 \\
\hline
\end{tabular}


In the original mutant as well as in those obtained as segregants in $F_{2}$ generation, stickiness was manifesting from late diplotene stage onwards and subsequent stages of meiosis were irregular as a consequence of the persistent stickiness, leading to pollen abortion. This is in contrast to the pioneer, report of sticky mutant in Zea mays (Beadle 1932) where the individual chromosomes fail to separate after zygotene pairing, and the mechanically torn apart chromatin forming numerous bridges and acentric fragments at later stages. Klein's (1971) meiotic mutant in Pisum resembles the present situation in that the somatic chromosomes were intact, in spite of the ill fated meiotic chromosomes. Rao and Rao (1977) in tomato and Mehra and Rao (1970) in Collinsia tinctoria on the other hand reported sticky chromosomes at prophase stage and reestablishment of individuality of chromosomes at later stages of meiosis. Persistent stickiness observed in the present study may possibly be the consequence of heritable changes in general physiology of the meiotic chromosomes such as interrupted synthesis of DNA as pointed out by Stern and Hotta (1966).

The genetic control appears to be of a monogenic recessive nature (Table 2). However, the number of mutant plants in $\mathrm{F}_{2}$ were lower than expected, which might be due to a general reduction in germination $(53 \%)$ as well as survival of seedlings $(47.2 \%)$. Frequency of abnormal cells in the mutant plants of $\mathrm{F}_{2}$, raised during winter season (day temperature $25 \pm 2^{\circ} \mathrm{C}$ )

Table 2. Meiotic behaviour and segregational pattern of $T_{4-1}$ in $F_{1}$ and $F_{2}$ generations

\begin{tabular}{|c|c|c|c|c|c|c|c|c|c|}
\hline \multirow{2}{*}{$\begin{array}{l}\text { S. } \\
\text { no. }\end{array}$} & \multirow{2}{*}{ Parameters studied } & \multirow{2}{*}{ Control } & \multirow{2}{*}{$\begin{array}{l}\text { Original } \\
\text { mutant }\end{array}$} & \multicolumn{2}{|c|}{$F_{1}$} & \multicolumn{2}{|c|}{$\mathbf{F}_{2}$} & \multirow{2}{*}{$\begin{array}{c}\chi^{2} \\
3: 1\end{array}$} & \multirow{2}{*}{$\begin{array}{c}\mathrm{p} \\
\text { value }\end{array}$} \\
\hline & & & & Normal & Mutant & Normal & Mutant & & \\
\hline 1 & Number of plants studied & 5 & 1 & 7 & 0 & 64 & 11 & 4.50 & $\begin{array}{l}0.05- \\
0.01\end{array}$ \\
\hline 2 & $\begin{array}{l}\text { Abnormal PMCs at post- } \\
\text { diakinesis stages ( } \%)\end{array}$ & 1.9 & $\begin{array}{l}89.2 \\
\pm 0.86\end{array}$ & 4.2 & - & 4.1 & $\begin{array}{l}69.5 \\
\pm 1.02\end{array}$ & & \\
\hline 3 & Abnormal sporads $(\%)$ & 0 & $\begin{array}{l}74.5 \\
\pm 1.41\end{array}$ & 0 & - & 1.1 & $\begin{array}{l}62.1 \\
\pm 1.23\end{array}$ & & \\
\hline 4 & Pollen sterility $(\%)$ & 10.1 & $\begin{array}{l}72.2 \\
\pm 0.38\end{array}$ & 16.2 & 一 & 12.3 & $\begin{array}{l}63.2 \\
\pm 0.81\end{array}$ & & \\
\hline 5 & Seed set per capsule & $\begin{array}{l}380 \\
\pm 0.91\end{array}$ & $\begin{array}{l}26 \\
\pm 0.54\end{array}$ & $\begin{array}{l}334 \\
\pm 0.87\end{array}$ & - & $\begin{array}{l}355 \\
\pm 0.54\end{array}$ & $\begin{array}{l}43 \\
\pm 1.05\end{array}$ & & \\
\hline
\end{tabular}

were lower than the parental values. It is likely that environmental factors, especially the summer temperatures $\left(31 \pm 1^{\circ} \mathrm{C}\right)$ prevailing at the time when the original mutant was isolated might have influenced the expression of the mutant gene. Analysis of variance for the frequencies of abnormal PMC and sporads in $\mathrm{F}_{2}$ showed no significant interplant variation. Appearance of mutant plants in $F_{2}$, as segregants from apparently normal disomic $F_{1}$ plants, suggests lack of relation of the mutant genes to trisomic condition.

b) Manifold meiotic abnormalities

In plant number $\mathrm{T}_{1-50}$ variability in the diameter of PMCs and the number of chromosomes per PMC was observed within the same anther (Figs. 2a, b, c). Frequencies of PMC at metaphase I showing 15,16 and 17 chromosomes were $16.64 \%, 49.79 \%$ and $28.17 \%$ respectively. PMCs with 9 to 14 chromosomes were less frequent. Quantitative estimation of different parameters in the mutant and control plants depicted in Table 3 indicates significant differences.

In few metaphase cells, as many as 34 chromosomes were seen iregularly dispersed in the cytoplasm (Fig. 2g), which may be the consequence of precocious second division split in all the 17 chromosomes and the failure of metaphase orientation. Unusually large PMCs with more than 56 chromosomes occasionally observed (Fig. 2 d) may be due to the formation of a 


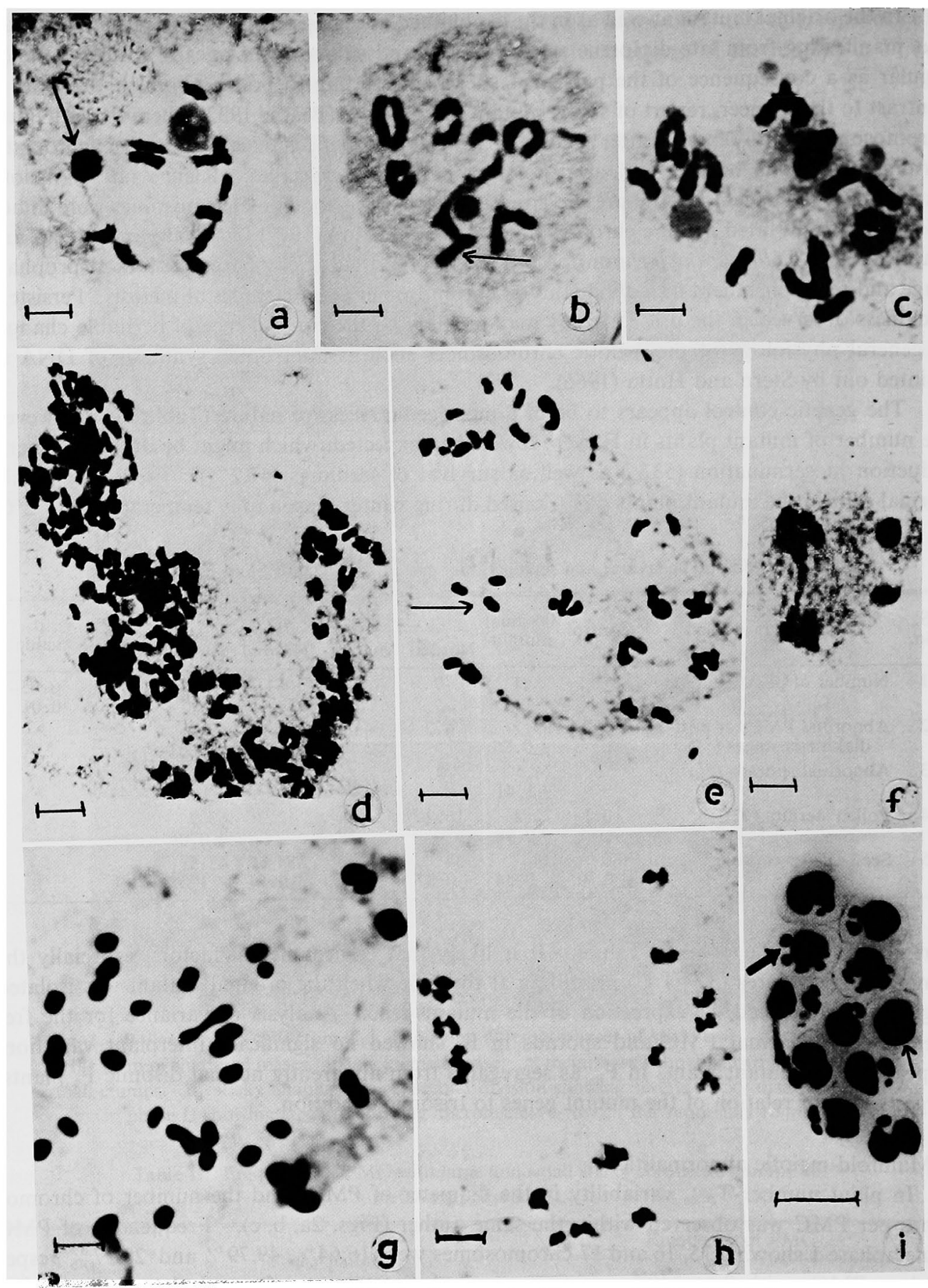

Fig. 2 (a to h). Meiotic abnormalities in plant number $T_{1-50}$. a, PMC with 11 chromosomes at diakinesis (extraneous particle indicated by arrow). b, PMC with 15 chromosomes at diakinesis6 bivalents +1 trivalent (arrow). c, diakinesis showing 17 chromosomes-7II $+3-$ I. d, polysomic condition at diakinesis. e, anaphase I with several laggards (arrow). f, unequal size of telophase II nuclei. g, diffused arrangement of chromosomes at metaphase I, and precocious second division split. $\mathrm{h}$, tripolar grouping at first division. i, sporads showing monad (small arrow) and polyad (large arrow) condition, and variation in size of the microspores in $T_{4-1}$. Bar represents 
syncyte as was also reported in Gossypium (Sarvella 1958) and in Pisum (Gottschalk 1970). Multipolar spindle abnormality at meiosis I, diffused arrangement of chromosomes at metaphase plates of both divisions, presence of several laggards and micronuclei ranging from 1 to 8 per cell were frequently encountered (Figs. 2e, f, h).

PMCs with different chromosome numbers showed no specific chimerae formation and were thoroughly mixed up with in the anther lobes. Chromosome numerical mosaicism may be the consequence of errors in premeiotic mitotic divisions due to defective spindle. The spindle abnormalities, especially the multiple and divergent spindle types lead to disrupted polar orientation, and the formation of several small nuclei, rather than two complete nuclei at telophase. Nevertheless, regardless of the number of chromosomes included, all the cells of the sporogenous tissue enter into meiosis, as is evident from the chromosome number of PMC, ranging from 9 to 17 . All the premeiotic mitotic cells may not exhibit the anomalous spindles, since in $49.79 \%$ of the cells, normal double trisomic condition prevailed. Variability in the number of chromosomes is reflected in a similar variability in PMC size.

On the other hand, variability in pollen size may be the consequence of spindle abnormalities at meiosis I, resulting in further exaggeration of the variation in chromosome number already installed at premeiotic mitotic divisions. Spindle abnormalities at second division were

Table 3. Meiotic behaviour in the mutant $T_{1-50}$

\begin{tabular}{|c|c|c|c|c|c|c|c|}
\hline \multirow{2}{*}{$\begin{array}{l}\text { S. } \\
\text { no. }\end{array}$} & \multirow{2}{*}{ Parameters studied } & \multicolumn{2}{|c|}{ Control } & \multicolumn{2}{|c|}{ Mutant } & \multirow{2}{*}{$\begin{array}{l}\text { ' } \mathrm{t} \text { ' } \\
\text { value }\end{array}$} & \multirow{2}{*}{$\begin{array}{l}\text { 'p' } \\
\text { value }\end{array}$} \\
\hline & & Range & Mean & Range & Mean & & \\
\hline 1 & Chromosome number & 14 & 14 & $9-17$ & 15.80 & & \\
\hline 2 & $\begin{array}{l}\text { Diameter of PMC } \\
\text { (in } \mu \mathrm{m})\end{array}$ & $58-63$ & $\begin{array}{l}61.8 \\
\pm 0.105\end{array}$ & $18-98$ & $\begin{array}{r}48.64 \\
\pm 4.92\end{array}$ & 2.67 & $<0.01$ \\
\hline 3 & Chiasma frequency & $8-13$ & $\begin{array}{c}10.06 \\
\pm 0.184\end{array}$ & $3-11$ & $\begin{array}{l}6.42 \\
\pm 1.61\end{array}$ & 2.24 & $<0.05$ \\
\hline 4 & $\begin{array}{l}\text { Pollen sterility } \\
\text { (in \%) }\end{array}$ & $6-15$ & $\begin{array}{l}10.1 \\
\pm 0.56\end{array}$ & $64-85$ & $\begin{array}{r}79.93 \\
\pm 1.85\end{array}$ & 36.18 & $<0.001$ \\
\hline 5 & $\begin{array}{l}\text { Diameter of pollen grains } \\
\text { (in } \mu \mathrm{m} \text { ) }\end{array}$ & $35-41$ & $\begin{array}{r}35.76 \\
\pm 0.801\end{array}$ & $20-65$ & $\begin{array}{r}30.51 \\
\pm 2.90\end{array}$ & 1.74 & $<0.10$ \\
\hline
\end{tabular}

not noticed in this material. Vasek (1962) in Clarkia exilis and Klein (1969) in Pisum sativum reported anbormal spindles at $M_{2}$ and normal behaviour at $M_{2}$ and concluded that $M_{1}$ and $\mathbf{M}_{2}$ spindles are under independent genetic control.

But the reasons whether intrinsic or extrinsic that were responsible for the errors to manifest, appear to be associated with aneuploidy and genetic imbalance. Chromosomal instability observed in Solanum nigrum complex was attributed to genetic disharmony, threshold effect of mutant genes with minor effects and certain environmental conditions (Venkateswarlu and Krishna Rao 1969). In the present study, meiotic abnormalities were confined to only one plant, among a number of aneuploid types, raised under similar environmental conditions, displaying normal meiotic behaviour (Padmaja 1979, Reddi and Padmaja 1982, Padmaja and Raddi 1984). Probably, apart from genetic imbalance, certain environmental conditions such as high summer temperatures are required for the expression of the mutant gene/genes. Darlington (1958) presumes that mutant genes are less buffered against environmental fluctuations and any change in environment could have greater effects on the manifestation of the mutant genes. But the exact nature and mode of inheritance of such gene/genes in this particular material could not be studied because of lack of seed set upon selfing as well as after crossing with sibs. 


\section{Summary}

Anomalus meiotic behaviour was recorded in two plants of $P$. axillaris (Lam.) B.S.P. $(2 \mathrm{n}=14)$. Meiotic irregularity was associated with diploid chromosome number in one plant, while in the other, chromosome instability and aneuploidy prevailed. Abnormalities such as persistent stickiness of chromosomes from late diplotene stage onwards, diffused arrangement of chromosomes at first metaphase, multipolar spindle abnormality, extreme variability in size of pollen mother cells and pollen grains, and syncyte formation were recorded. Chromosome stickiness observed in one category was attributed to a recessive gene, the expression of which was influenced by temperature, while variation in chromosome number and multiple meiotic anomalies recorded in the other may be due to spindle abnormalities at premeiotic mitotic cell divisions and at meiosis $\mathbf{I}$.

\section{References}

Baker, S., Carpenter, A. T. C., Esposito, M. S., Esposito, R. E. and Sanoler, L. 1976. The genetic control of meiosis. Ann. Rev. Genet. 10: 53-134.

Beadle, G. W. 1932. A gene for sticky chromosomes in Zea mays 2. Indukt. Abstamn. Vererbungsl. 63: 195-217.

Darlington, C. D. 1958. Evolution of Genetic Systems. Edinburgh, Oliver \& Boyd.

Gottschalk, W. 1968. Investigations on the genetic control of meiosis. Nucleus, Suppl. on Chromosomes. pp. 345-360.

- 1970. Chromosome and nucleus migration during microsporogenesis of Pismu sativum. Nucleus 13(1): 1-9.

Gowen, M. S. and Gowen, J. W. 1922. Complete linkage in Drosophila melanagaster. Am. Nat. 56: 286-288.

John, B. and Lewis, K. R. 1965. The Meiotic System. Protoplasmologia. Band VI/F/1, Vienna and New York, Springer.

Kaul, M. L. H. and Murthy, T. G. K. 1985. Mutant genes affecting higher plant meiosis. Theor. Appl. Genet. 70: $449-466$.

Klein, N. D. 1969. Desynaptische Mutanten mit Unterschieden im Univalentenverhalten. Genetica 40: 566576.

- 1971. Eine Pisum-Mutante mit zahlreichen meiotischen Störungen. Cytologia 36: 15-25.

Mehra, R. L., and Rai, K. S. 1970. Cytogenetic studies of meiotic abnormalities in Collinsia tinctoria 1. Chromosome stickiness. Can. J. Genet. Cytol. 12: 560-569.

Padmaja, V. 1979. Cytogenetics of induced mutants and polyploids in garden Petunia. Ph. D. Thesis, Andhra University, Waltair, India.

- and V. R. Reddi. 1984. Studies on aneuploids of Petunia II. A tertiary trisomic for chromosomes 2 and 3 $(2 n+2 S .3 L)$. J. Cytol. Genet. 19: 1-3.

Rao, P. N. and Rao, R. N. 1977. Gamma ray induced meiotic chromosomes stickiness in tomato. Theor. Appl. Genet. 50: 247-252.

Reddi, V. R. and Padmaja, V. 1982. Studies on aneuploids of Petunia Part I. Cytomorphological identification of primary trisomics. Theor. Appl. Genet. 61: 35-40.

Riley, R. 1966. Genetics and the regulation of meiotic chromosome behaviour. Sci. Prog. 53: 193-207.

Sarvella, P. 1958. Cytomixis and the loss of chromosomes in meiotic and somatic cells of Gossypium. Cytologia 23: 14-24.

Stern, H. and Hotta, Y. 1966. Chromosome behaviour during development of meiotic tissue. In: Lester Goldstein (ed.) The Control of Nnuclear Activity. Prentice Hall, Inc.

Taylor, J. H. 1967. Meiosis. In Encyclopedia of Plant Physiology 18: 344-367. Berlin, Heidelberg \& New York, Springer.

Vasek, F. C. 1962. Multiple spindle-a meiotic irregularity in Clarkia exilis. Am. J. Bot. 49: 536-539.

Venkateswarlu, J. and Krishna Rao, M. 1969. Chromosome numerical mosaicism in some hybrids of Solanum nigrum complex. Genetica. 40: 400-406. 